\title{
FORMATION OF GLYCIDYL ESTERS DURING THE DEODORIZATION OF VEGETABLE OILS
}

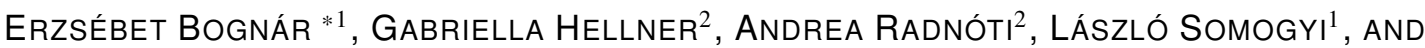 \\ ZSOLT KEMÉNY²
}
'Department of Grain and Industrial Plant Processing, Szent István University, Villányi út 29-43, Budapest, 1118, HUNGARY
${ }^{2}$ BEMEA Katalin Kővári R\&D Centre, lllatos út 38, Budapest, 1097, HUNGARY

\begin{abstract}
Glycidyl esters are foodborne contaminants formed during the production of fats and oils, especially during the deodorization of palm oil. The hydrolyzed free form of glycidol has been categorized as probably carcinogenic to humans by the World Health Organization's International Agency for Research on Cancer. The aim of this research was to study the formation of glycidyl esters during the lab-scale deodorization of the three most widely produced seed oils in the world (sunflower, rapeseed and soybean). The effects of two independent factors - temperature and residence time - were analyzed by a $3^{2}$ full factorial experimental design and evaluated by response surface methodology. In accordance with findings in the literature, the greatest amount of glycidyl esters was formed in the soybean oil matrix. For all three oils, the effects of both residence time and temperature were significant, while the latter was more so. To reduce the formation of glycidyl esters, milder deodorization is required, which is limited because of the purposes sought by the thermal operation and removal of volatile minor components and contaminants.
\end{abstract}

Keywords: glycidyl esters, deodorization, seed oils

\section{Introduction}

Glycidyl esters (GEs) are foodborne contaminants formed in fat-containing food and food ingredients during high-temperature thermal treatment. According to previous studies, glycidol is produced during digestion from the enzymatic hydrolysis of GEs [1,2]. The IARC (International Agency for Research on Cancer) has listed glycidol as a Group 2A or genotoxic carcinogen [3]. This year, the European Commission adopted the Commission Regulation (EU) 2018/290 that stipulates the maximum level of glycidyl fatty acid esters permitted in vegetable oils and fats, infant formula, follow-on formula and foods for special medical purposes intended for infants and young children. The maximum concentration of glycidyl fatty acid esters is $1 \mathrm{mg} / \mathrm{kg}$ in vegetable oils and fats placed on the market for end consumers or for use as an ingredient in food, and $0.5 \mathrm{mg} / \mathrm{kg}$ for vegetable oils and fats destined for the production of baby food and processed cereal-based food for infants and young children [4].

GEs are formed in vegetable oils during the refining process in the deodorization step, which is conducted at high temperatures $\left(200-275^{\circ} \mathrm{C}\right.$ ) under vacuum (of less than 10 mbar residual pressure) [5,6]. Deodorization is the last step of refining of conventional edible oils and is intended to remove undesirable substances in order to im-

\footnotetext{
*Correspondence: zsofi.bognar@outlook.hu
}

prove the taste, odor, color and oxidative stability of such oils [7]. According to data from the literature, high levels of GEs are primarily measured in refined palm oil and its fractions. Destaillats et al. [8] showed in their study that GEs are formed from di- and monoacylglycerols (DAGs and MAGs), but not from triacylglycerols (TAGs). Accordingly, high levels of GE can be traced back to high levels of DAGs in crude palm oil [8]. The formation of GE starts at about $200{ }^{\circ} \mathrm{C}$ [8].

Analytical methods for the determination of GEs can be divided into two main groups: direct and indirect methods [9]. Individual GEs are determined by direct quantitation methods which are mainly based on liquid chromatography-mass spectrometry (LC-MS), requiring a significant number of reference compounds and internal standards $[10,11]$. Indirect determination is based on the conversion of GEs into glycidol which is then isolated, derivatized, chromatographically separated and quantified. The result is expressed as the amount of glycidol that can be released from GEs. These methods require only a small number of internal standards [9].

In our study, the quantity of GEs in seed oil during lab-scale deodorization was determined in order to examine the effects of two independent factors - temperature and residence time - on the formation of GEs. 


\section{Experimental}

\subsection{Samples and Measurements}

Bleached sunflower, rapeseed and soybean oils were supplied by Bunge Limited (Bunge Zrt. Hungary and Bunge Ibérica, S.A.U.). Diethyl ether, ethyl acetate, $n$-hexane and high-performance liquid chromatography (HPLC)grade water were obtained from VWR International Kft. (Debrecen, Hungary). Toluene, isohexane, sodium bromide and phenylboronic acid were obtained from Merck Kft. (Budapest, Hungary). Methanol, sodium hydroxide and anhydrous sodium sulfate were purchased from Reanal Laborvegyszer Kft. (Budapest, Hungary). The internal standards glycidyl palmitate- $d_{5}$ and 3-chloro-1,2propanediol- $d_{5}$ (3-MCPD- $d_{5}$ ) were obtained from LabStandards (Budapest, Hungary). All reagents and chemicals were of analytical grade.

Lab-scale deodorization trials were conducted in 150 $\mathrm{g}$ batches at temperatures between 220 and $260{ }^{\circ} \mathrm{C}$. The bleached oils (sunflower, rapeseed or soybean) were heated to the target temperature $(220,230,240,250$ or $260{ }^{\circ} \mathrm{C}$ ) within $10-15$ minutes. The process lasted 3 hours at a pressure of 3-4 mbar using nitrogen as a stripping gas. Without breaking the vacuum, sampling was conducted after $0,15,30,45,60,90,120$ and 150 minutes had elapsed.

The quantities of glycidyl esters were determined using the American Oil Chemists' Society (AOCS) Official Method Cd 29b-13, which is based on alkalinecatalyzed ester cleavage and transformation of the released glycidol into monobromopropanediol (MBPD) and derived free diols using phenylboronic acid (PBA). These derivatives are measured by the Gas Chromatography/Mass Spectrometry (GC/MS) coupled system (Agilent 6890 coupled with 5973) in the selected ion monitoring (SIM) mode. Quantitative determination was based on the deuterated internal standard using characteristic ions for derivatised glycidol- $d_{5}$ at $\mathrm{m} / \mathrm{z} 150$ and 245 , and derivatised glycidol at m/z 147 and 240 .

\subsection{Experimental design and statistical anal- ysis}

The temperature and residence time were studied using response surface methodology (RSM). The results of the $3^{2}$ full factorial experimental design (see Table 1) were evaluated by analysis of variance (ANOVA) models using Statistica 13. The center point of the $3^{2}$ full factorial design (mid temperature $240{ }^{\circ} \mathrm{C}$ ) and mid time 90 minutes) was repeated three times.

Only the significant effects (of main effects and interactions) were taken into account in the response surface methodology. The generalized polynomial model for describing the response of independent variables is given in

$$
\begin{aligned}
y & =\beta_{0}+\beta_{1} X_{1}+\beta_{2} X_{1}^{2}+\beta_{3} X_{2}+ \\
& +\beta_{4} X_{2}^{2}+\beta_{5} X_{1} X_{2}+\beta_{6} X_{1} X_{2}^{2}+ \\
& +\beta_{7} X_{1}^{2} X_{2}+\beta_{8} X_{1}^{2} X_{2}^{2}
\end{aligned}
$$

Table 1: $3^{2}$ full factorial experimental design

\begin{tabular}{lllll}
\hline Independent variables & \multicolumn{3}{c}{ Levels } \\
& & -1 & 0 & +1 \\
\hline $\mathrm{X} 1$ & Temperature $\left({ }^{\circ} \mathrm{C}\right)$ & 220 & 240 & 260 \\
$\mathrm{X} 2$ & Residence time (min) & 0 & 90 & 180 \\
\hline \multicolumn{2}{l}{ Dependent Variables (Yi) Glycidyl esters (mg/kg) } \\
\hline
\end{tabular}

\section{Results and Evaluation}

\subsection{Experiments}

The results of the lab-scale investigation of GE formation are shown in Fig. 1. In our experimental design, the greatest amount of GEs formed in soybean oil, in which the concentration of GEs reached $5.5 \mathrm{mg} / \mathrm{kg}$ at $260{ }^{\circ} \mathrm{C}$ after 180 minutes (Fig. 1A). In the sunflower and rapeseed oils, the maximum concentrations of GEs reached were 1.6 and $1.5 \mathrm{mg} / \mathrm{kg}$, respectively (Figs. $1 \mathrm{~B}$ and $1 \mathrm{C}$ ). The GE content of sunflower and rapeseed oils was kept under $1 \mathrm{mg} / \mathrm{kg}$ after 120 minutes of deodorization at a temperature of $250{ }^{\circ} \mathrm{C}$ or less, but for soybean oil this level was obtained at or below $230{ }^{\circ} \mathrm{C}$. This demonstrates that the amounts of precursors in the oils strongly influence the formation of GE, and consequently the optimal deodorization temperature. The threshold concentration of
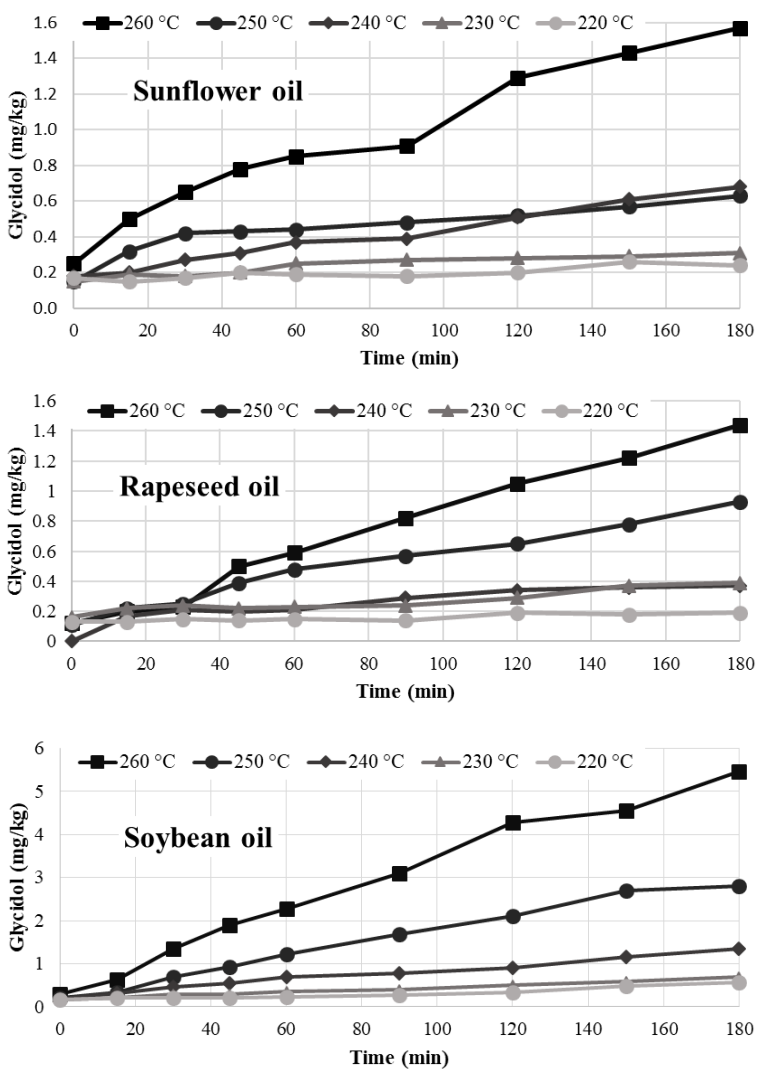

Figure 1: GEs of seed oils during deodorization: A) sunflower oil, B) rapeseed oil, C) soybean oil 


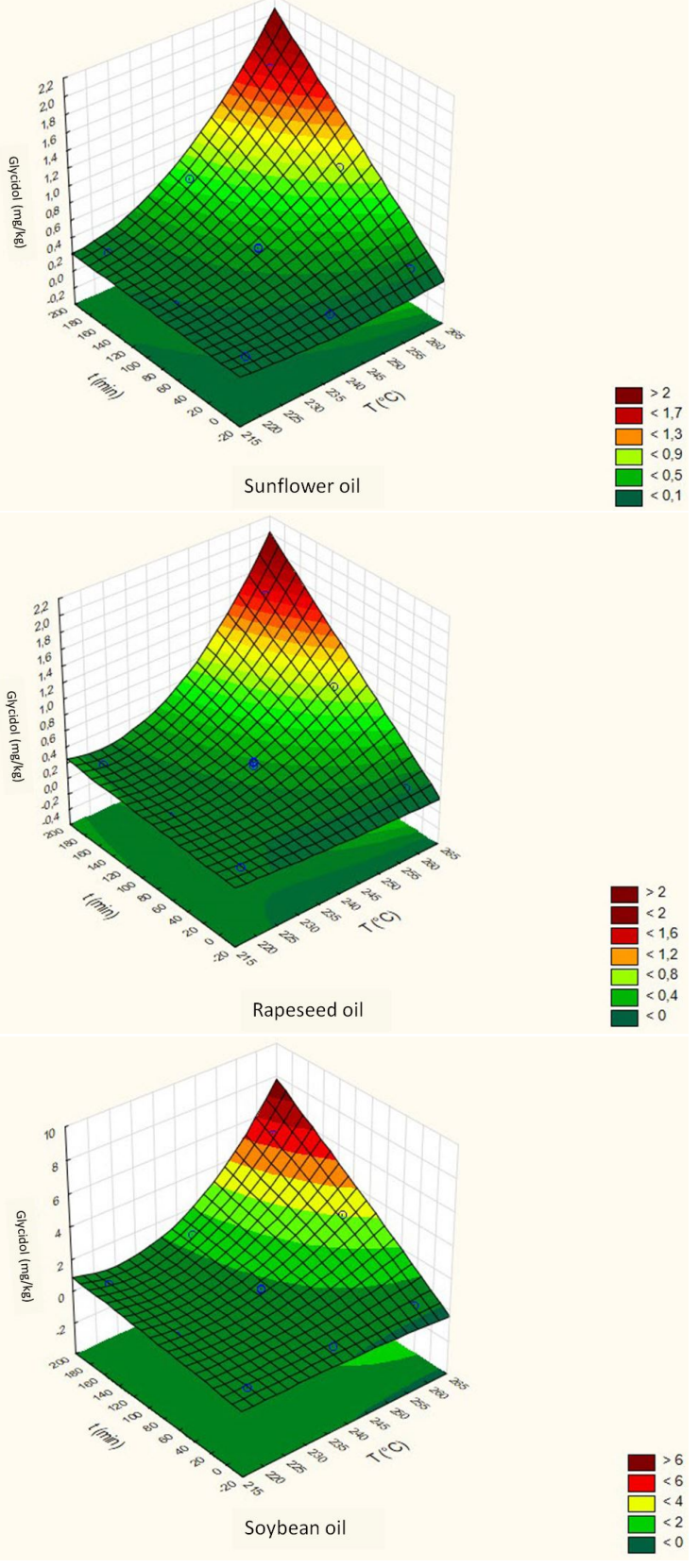

Figure 2: Fitted surfaces for seed oils: A) sunflower oil, B) rapeseed oil, C) soybean oil

$0.5 \mathrm{mg} / \mathrm{kg}$ permitted for infant food was complied with at 240,230 and $220{ }^{\circ} \mathrm{C}$ for rapeseed, sunflower and soybean oils, respectively (after 120 minutes of deodorization). In the applied experimental setup, up to $0.3 \mathrm{mg} / \mathrm{kg}$ of GE formed after 10-15 minutes of heating. At lower deodorization temperatures, the effect of time becomes practically insignificant, especially at 220 and $230{ }^{\circ} \mathrm{C}$.

\subsection{Statistical analysis}

The application of RSM allowed the main effects and interactions to be determined simultaneously. ANOVA shows the significant effects, which can be used for build-
Table 2: Regression coefficients for intercept $(I)$, linear and quadratic factors, as well as interactions between factors in the fitted models of seed oils

\begin{tabular}{llll}
\hline & Sunflower oil & Rapeseed oil & Soybean oil \\
\hline$I$ & 7.95 & 7.12 & 10.32 \\
$T$ & $-6.72 \times 10^{-2}$ & $-5.9 \times 10^{-2}$ & $-9.02 \times 10^{-2}$ \\
$T^{2}$ & $1.45 \times 10^{-4}$ & $1.23 \times 10^{-4}$ & $2 \times 10^{-4}$ \\
$t$ & $1.17 \times 10^{-1}$ & $2.16 \times 10^{-1}$ & 1.14 \\
$t^{2}$ & n.s. & n.s. & n.s. \\
$T t$ & $-1.13 \times 10^{-3}$ & $-1.96 \times 10^{-3}$ & $-1.01 \times 10^{-2}$ \\
$T^{2} t$ & $3 \times 10^{-5}$ & $4 \times 10^{-5}$ & $2.2 \times 10^{-5}$ \\
$T t^{2}$ & n.s. & n.s. & $-2.38 \times 10^{-8}$ \\
\hline
\end{tabular}

n.s.: effect not significant

ing the response surface model. The fitted surfaces for sunflower, rapeseed and soybean oils are presented in Figs. 2A-C, respectively. The shapes of the surfaces are very similar, the only difference is in their heights. The interactions between the independent variables can be observed from the fitted surfaces, because at lower temperatures the concentrations of GEs gradually increased over time, while at higher temperatures a more rapid increase occurred.

For all three seed oils the temperature had the largest effect. The interaction between the independent variables and the effect of time were the second and third most significant, but the quadratic components and their interactions with the other factors were noticeable in most cases, as well. The regression coefficients are shown in Table 2 coefficients in the case of sunflower and rapeseed oils are very similar so the RSM diagrams of these oils fall within the same range of values (Figs. 2A and 2B).

\section{Discussion}

According to the data from the literature, the oil that has been studied the most in this respect is palm oil along with its fractions [8,12]. Cheng et al. [13] summarized the data from previous studies and according to this review the highest concentrations of GEs in seed oil were found in soybean oil when compared to rapeseed and sunflower oils. This is in agreement with our observations. The higher concentrations of GEs that formed during deodorization were due to the higher levels of DAGs and MAGs in the raw material.

It was found that the critical temperature range is between 220 and $240{ }^{\circ} \mathrm{C}$, above which more than $0.5 \mathrm{mg} / \mathrm{kg}$ of GEs may form, depending on the quality of the raw material. This conclusion is similar to the results of previous investigations. Craft et al. [12] concluded that between 230 and $240{ }^{\circ} \mathrm{C}$, the formation of GE is extensive, consequently this value should be considered as an upper limit for the deodorization process. De Kock et al. [14] suggested conducting deodorization for a longer period 
of time at temperatures below $240{ }^{\circ} \mathrm{C}$, which might also minimize the formation of trans fatty acids.

\section{Conclusion}

The present investigation suggests that the formation of GEs in seed oils during deodorization is not negligible. The rate of formation can be traced back to the level of DAGs and MAGs [15] in the raw material. A simultaneous increase in temperature and time could result in extremely high levels of GEs in oils. On an industrial scale, the formation of GEs can be controlled in the oils examined, meaning that the upper limit of GEs (1 $\mathrm{mg} / \mathrm{kg}$ ) in vegetable oils and fats placed on the market for general consumption can be achieved through preventive measures. The stricter limit imposed on oils destined for the production of food for infants and young children presents greater challenges, and thus requires a combination of high quality raw materials as well as a controlled refining process.

\section{Acknowledgement}

Funding for this research was provided by the Doctoral School of Food Sciences at Szent István University (Budapest) and by the BEMEA Katalin Kövári R\&D Centre. The Project is supported by the European Union and cofinanced by the European Social Fund (grant agreement no. EFOP-3.6.3-VEKOP-16-2017-00005).

\section{Symbols}

$\begin{array}{ll}\beta_{0-8} & \begin{array}{l}\text { Regression coefficients for intercept, linear } \\ \text { and quadratic factors and interactions } \\ \text { between factors }\end{array} \\ X_{1}, X_{2} & \begin{array}{l}\text { Independent factors } \\ T\end{array} \\ t & \begin{array}{l}\text { Deodorization temperature } \\ \text { Deodorization time }\end{array}\end{array}$

\section{REFERENCES}

[1] Appel, K.E.; Abraham, K.; Berge-Preiss, E.; Hansen, T.; Apel, E.; Schuchardt, S.; Vogt, C.; Bakhiya, N.; Creutzenberg, O.; Lampen, A.: Relative oral bioavailability of glycidol from glycidyl fatty acid esters in rats, Arch. Toxicol., 2013 87(9), 1649-1659 DOI: 10.1007/s00204-013-1061-1

[2] Frank, N.; Dubois, M.; Scholz, G.; Seefelder, W.; Chuat, J.-Y.; Schilter, B.: Application of gastrointestinal modelling to the study of the digestion and transformation of dietary glycidyl esters, Food Addit. Contam. Part A, 2013 30(1), 69-79 DOI: 10.1016/j.foodchem.2010.08.036

[3] IARC (International Agency for Research on Cancer): Glycidol, In: IARC Monographs Volume 77. On the evaluation of carcinogenic risks to humans (WHO Press, Lyon, France) 2000 pp. 469-486 ISBN: 9283212770
[4] Official Journal of the European Union: COMMISSION REGULATION (EU) 2018/290 of 26 February 2018 amending Regulation (EC) No 1881/2006 as regards maximum levels of glycidyl fatty acid esters in vegetable oils and fats, infant formula, follow-on formula and foods for special medical purposes intended for infants and young children 2018

[5] Carlson, F.K.: Deodorization. In: Hui, Y. H. (ed.) Bailey's industrial oil and fat products. Edible oil and fat products: Processing technology. 5th Edition. Volume 4. (John Wiley \& Sons Inc., New York, USA) 1996 pp. 411-449 ISBN: 9780471594284

[6] O'Brien, R.D.: Fats and oils formulating and processing for applications. Third Edition. (CRC Press Taylor \& Francis Group, Boca Raton, Florida, USA) 2009 pp. 153-164 ISBN: 9781420061666

[7] Sipos, E.F.; Szuhaj, B.F.: Edible oil Processing. In: Hui, Y.H. (ed.) Bailey's industrial oil and fat products. Edible oil and fat products: Oils and oilseeds. 5th Edition. Volume 2. (John Wiley \& Sons Inc., New York, USA) 1996 pp. 497-602 ISBN: 9780471594260

[8] Destaillats, F.; Craft, B.D.; Dubois, M.; Nagy, K.: Glycidyl esters in refined palm (Elaeis guineensis) oil and related fractions. Part I: Formation mechanism, Food Chem., 2012 131(4), 1391-1398 DOI: 10.1016/j.foodchem.2011.10.006

[9] Ermacora, A.; Hrncirik, K.: Indirect detection techniques for MCPD esters and glycidyl esters. In: MacMahon, S. (ed.) Processing contaminants in edible oils MCPD and glycidyl esters (AOCS Press, Urbana, USA) 2014 pp. 57-90 ISBN: 9780988856509

[10] Thürer, A.; Granvogl, M.: Direct detection techniques for glycidyl esters. In: MacMahon, S. (ed.) Processing contaminants in edible oils MCPD and glycidyl esters (AOCS Press, Urbana, USA) 2014 pp. 91-120 ISBN: 9780988856509

[11] Blumhorst, M.R.; Venkitasubramanian, P.; Collison, M.W.: Direct determination of glycidyl esters of fatty acids in vegetable oils by LC-MS, $J$. Am. Oil Chem. Soc., 2011 88(9), 1275-1283 DOI: 10.1007/s11746-011-1873-1

[12] Craft, B.D.; Nagy, K.; Seefelder, W.; Dubois, M.; Destaillats, F.: Glycidyl esters in refined palm (Elaeis guineensis) oil and related fractions. Part II: Practical recommendations for effective mitigation, Food Chem., 2012 132(1), 73-79 DOI: 10.1016/j.foodchem.2011.10.034

[13] Cheng, W.W.; Liu, G.Q.; Wang, L.Q.; Liu, Z.S.: Glycidyl Fatty Acid Esters in Refined Edible Oils: A review on formation, occurrence, analysis, and elimination methods, Compr. Rev. Food Sci. F., 2017 16(2), 263-281 DOI: 10.1111/1541-4337.12251

[14] De Kock, J.; Papastergiadis, A.; De Greyt, W.: Technological solutions and developments in edible oil processing to minimize contaminants in various oils and fats. 5th Leipzig Symposium 'Processing and 
Analytics: How does co-operation work in Practice?' (9-10 March 2016, Leipzig, Germany) 2016

[15] Csányi, E., Bélafi-Bakó, K.: Semi-continuous fatty acid production by lipase, Hung. J. Ind. Chem., 1999 27(4), 293-295 